\title{
THE UTILIZATION OF VISUAL BASIC.NET APPLICATION FOR DETERMINATION OF INDIVIDUAL DRUG DOSAGES IN DIABETIC PATIENTS OF CHRONIC RENAL DISORDER COMPLICATIONS
}

\author{
ARI USMAN ${ }^{1}$, NILSYA FEBRIKA ZEBUA ${ }^{2 *}$ \\ ${ }^{1}$ Department of Informatics Engineering, Universitas Harapan Medan, Medan, Indonesia. ${ }^{2}$ Departmentof Pharmacy, Universitas Tjut Nyak \\ Dhien, Medan, Indonesia. Email: nilsya.zebua@gmail.com
}

Received: 25 October 2017, Revised and Accepted: 13 March 2018

\section{ABSTRACT}

Objective: This research aims to apply the Visual Basic.Net (VB.NET) of individual dose calculations based on the formula of pharmacokinetics for diabetic patients of chronic renal disorder complication in Dr. Pirngadi Hospital because the dosage administered was not based on the patient's creatinine clearance.

Methods: This descriptive research was conducted using a simulated creatinine cleavage calculation using VB.NET programming language applications with variable patient data, the value of creatinine, the name of drug, and dosage.

Results: This study used visual basic.net applications and obtained data on drug use 40 patients consisting of $40 \%$ male and $60 \%$ female, age $41-70$ years, creatinine clearance $<50 \mathrm{~mL} / \mathrm{min}$. There are 4 types of drugs over the dose based on creatinine clearance calculations of ceftriaxone (18 of 18 cases), furosemide (19 of 19 cases), ciprofloxacin ( 2 of 8 cases), and ranitidine ( 4 of 24 cases). There are 2 types of drugs that are less than the dose of pharmacokinetic calculations of metformin ( 2 of 7 cases) and captopril (16 of 16 cases).

Conclusions: Research has successfully implemented visual basic.net. to calculate the individual dose of patients with complicated diabetic kidney failure quickly and easily.

Keywords: Visual Basic.Net, Drug dosage, Pharmacokinetic calculations.

(c) 2018 The Authors. Published by Innovare Academic Sciences Pvt Ltd. This is an open access article under the CC BY license (http://creativecommons. org/licenses/by/4. 0/) DOI: http://dx.doi.org/10.22159/ajpcr.2018.v11s1.26616

\section{NTRODUCTION}

Diabetes mellitus (DM) is one of the health problems that affect productivity and can decrease the quality of human resources that its prevalence will continue to increase from year to year. DM is a degenerative disease characterized by hyperglycemia associated with abnormalities of carbohydrate metabolism, fats, and proteins caused by decreased insulin sensitivity or both and leads to complications [1]. Complications include frequent microvascular complications of diabetic nephropathy, i.e., kidney DM complications that may end up as renal failure. Kidney failure can occur as a result of the disease itself and may result from the long-term use of DM drugs. Drugs expressed through the kidneys will accumulate in the presence of impaired renal function and may cause toxic effects or worsen the patient's renal condition if the dose is not adjusted [2].

Most water-soluble drugs are excreted in a certain amount in the intact form through the kidneys. Doses of these drugs, especially those with narrow therapeutic window drugs, need careful adjustment when prescribed to patients with decreased renal function [3]. Accumulation of plasma drug levels may occur and minimum toxic levels may be missed if doses are not calculated on the patient's renal function. Most drugs also have a damaging effect on the kidneys (nephrotoxic), so the dosage should also be adjusted for patients with decreased renal function [4].

Dose adjustment strategies in patients with renal failure may be helpful in individual drug therapy and may prevent further deterioration in the quality of life of the patient [5]. The recommended method of adjusting the dose is to reduce the dose, extend the dose interval, or a combination of both [6]. Clinical pharmacokinetics is an application of the pharmacokinetic method for drug therapy which includes a multidisciplinary approach to individual optimal dosing strategies based on patient disease conditions and specific patient considerations [2].

The success rate of diabetes therapy not only provides patient guarantees about rational treatment alone but also knowledge of clinical pharmacokinetic aspects is also very important to ensure that drugs used so as to relieve renal work and drug effectiveness can be achieved. Long-term diabetes drug therapy should be followed by monitoring of renal function by looking at creatinine clearance so that dose adjustment can be made if kidney function declines [7]

The principle of pharmacokinetics in humans aims at making individual dosage regimens by optimizing therapeutic response to treatment and minimizing side effects. Pharmacokinetics is a branch of pharmacology that is associated with the determination of the fate of the drug in the body, which includes absorbs, distribution, metabolism, and excretion. Clinical pharmacokinetics is the application of pharmacokinetic principles to the safe and effective management of drug therapy in a patient so that the success of drug therapy can be optimal [1]. The use of antidiabetic drugs in renal impairment is necessary in clinical pharmacokinetic principle because with the occurrence of kidney degradation, the drugs expressed through the kidneys will accumulate and may cause toxic effects or worsen the patient's renal condition, so dose adjustment is necessary [2].

Visual Basic.Net (VB.NET) is one of the high-level computer programming languages. One programming language is the object-oriented program or object-oriented programming. The word "Visual" shows the way that is used to create a graphical user interface. Now, Microsoft has been able to realize the vision of "Windows operating system in every PC and PC in every desktop." One tool for developing.NET applications is Microsoft VB.NET. VB.NET along with Visual C++.NET, Visual C\#.NET, Visual J++. NET, and Visual J\#.NET is a part of Microsoft Visual Studio.NET. VB.NET can also work with database applications that can hold data using SQL server. Excess VB.NET is used for calculation of individual doses based on creatinine clearance, so it can be easily applied to health facilities [8]. This research aims to apply the VB.NET of individual dose calculations based on the formula of pharmacokinetics for diabetic patients of chronic renal disorder complication in Dr. Pirngadi Hospital because so far the dosage administered was not based on the patient's creatinine clearance. 


\section{MATERIALS AND METHODS}

The study was conducted at Dr. Pirngadi Hospital Medan on JulyAugust 2017. The patient data were collected in a limited population at the inpatient hospital in RSUD Dr.Pirngadi Medan. The inclusion criteria were patients with a diagnosis of acute and chronic renal failure, patients with creatinine clearance $<80 \mathrm{~mL} / \mathrm{min}$, and patients receiving drug therapy were eliminated mainly through the kidneys. Patients with a diagnosis of diabetes complication of renal failure are identified, treatment data along with laboratory data. Next, we calculated the creatinine clearance value with an equation that matched the available data and the general condition of the patient. The methods used in creatinine clearance calculations include the Cockroft and Gault formula (Method 1), the Jellife and Jellife formula (Method 2) specifically for patients with unstable creatinine serum values, and Salazar and Corcoran formula (Method 3) formulas for obese patients. After creatinine clearance was calculated by an appropriate equation, a dosage adjustment calculation for drugs excreted primarily through the kidneys, a class of nephrotoxic drugs and a class of drugs with a narrow therapeutic index secreted through the kidneys. The method that can be used in dose adjustment is the method of drug excretion fraction in the intact form. The dose adjustment was calculated using the Giusti-Hayton formula using the fraction drug values expressed in whole form (fe) for each drug that required dose adjustment. For most drugs, fe values have been present in the literature.

\section{RESULTS}

Pharmacokinetic analysis using applications built using the Visual Basic.Net programming language for the determination of drug doses in patients with diabetes mellitus complications of renal failure in RSUD Dr. Pirngadi Medan. The study obtained 320 cases but only 40 patients met the complete criteria consisting of 16 male and 24 female, 10 patients aged $41-50$ years, 20 patients aged $51-60$ years and 10 patients with 61-70 years of age, 2 patients with creatinine clearance $30-50 \mathrm{~mL} / \mathrm{min}$ and the rest $<30 \mathrm{~mL} / \mathrm{min}$. Based on data on the use of drugs to 40 patients, there are 6 types of drugs which are drugs that are largely excreted through the kidney in the form of unchanged ceftriaxone ( $\mathrm{fe}=40-65 \% \mathrm{iv}, 18$ cases), furosemide ( $\mathrm{fe}=74 \%, 19$ cases), ranitidine (fe $=50 \%$ oral, $>70 \%$ iv, 24), ciprofloxacin (fe $=40-50 \%$ oral, $70 \%$ IV, 8 cases), captopril (fe $=75 \%, 16$ cases), and metformin ( $\mathrm{fe}=$ $60 \%, 7$ cases). Patient's demography and cases of medication can be seen in Table 1 and Table 2.

\section{DISCUSSION}

After using the visual basic programming language application as shown in Fig. 1, a drug dose adjustment for patients with chronic renal impairment in Figs. 2-8 is obtained. IMethod 2 is not be used in this study because creatinine measurement is generally performed only once. The patient also excludes obese patients so that Figs. 2-5shows a comparison chart between the usual dosage, the dose administered in the hospital, and the dose of calculation based on creatinine clearance using method 1.

The use of ranitidine was used by 24 patients from the 40 patients observed. Based on pharmacokinetic calculations, 3 cases of intravenous administration of P3 (doses administered $100 \mathrm{mg}$ over a creatinine clearance dose count of $90 \mathrm{mg}$ ), P8 (dose administered $150 \mathrm{mg}$ over creatinine clearance dose of $120 \mathrm{mg}$ ), P38 (given dose $100 \mathrm{mg}$ over the calculated creatinine clearance dose of $90 \mathrm{mg}$ ), whereas 1 case is P22 (given $200 \mathrm{mg}$ dose over creatinine clearance dose of $180 \mathrm{mg}$ ). The differences between the doses administered and the dose calculations based on creatinine clearance were not significantly different $(P<0.01)$. Fig. 2 shows that the physician at the Pirngadi Hospital has attempted to reduce the dose of administration of the drug to the diabetic patient with renal impairment, but this is done not on the exact pharmacokinetic calculation so that there are 4 cases of administration doses that exceed the pharmacokinetic dose calculation and 15 cases less than the dose which should be given based on the patient's creatinine clearance calculations. Basic.net

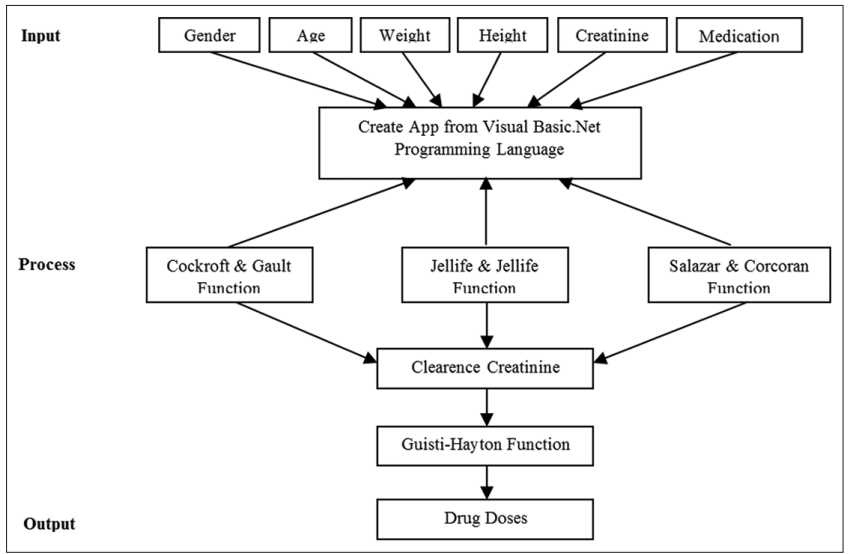

Fig. 1: Flow of process application

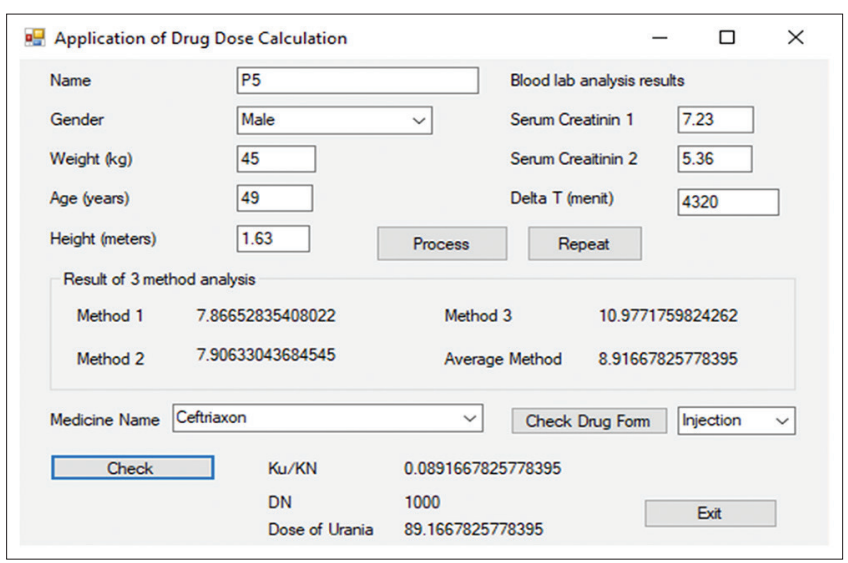

Fig. 2: Implementation of individual dose calculation application [9]

visual applications can quickly calculate the dose that should be given to the patient based on the patient's creatinine clearance so that no errors in the dosage drug of the diabetic patients for renal failure are made [9]. Ranitidine is excreted through the kidneys in unchanged about $50 \%$ for oral and $>70 \%$ for intravenous. Patients with creatinine clearance $<50 \mathrm{~mL} / \mathrm{min}$ recommended oral dose is $150 \mathrm{mg} /$ day, with increased dose monitoring to $150 \mathrm{mg} / 12 \mathrm{~h}$, while for intravenous doses, some countries have different recommendations. In the UK, the recommended intravenous dose is $25 \mathrm{mg}$ /day with a customized frequency, whereas in the United States, the recommended intravenous dose is $50 \mathrm{mg} /$ day for $18 / 24 \mathrm{~h}$, which may increase easily to every $12 \mathrm{~h}$ or more often if necessary [10].

Ciprofloxacin is a drug with a wide therapeutic index that has a fairly high level of safety, but doses in patients with renal failure should be adjusted, especially patients with creatinine clearance $<50 \mathrm{~mL} / \mathrm{min}$ to avoid elevated levels of the drug in the blood that will aggravate kidney work [11]. The result data showed 2 of 8 cases of ciprofloxacin use exceeded the calculated dose based on renal function of patients using pharmacokinetic equation, i.e., on P3 (dose administered $1000 \mathrm{mg}$ over the creatinine clearance dose count of $400 \mathrm{mg}$ ) and P19 (dose administered $1000 \mathrm{mg}$ over dose calculation of creatinine clearance of $600 \mathrm{mg}$ ). The difference between the doses administered and the dose of pharmacokinetic calculation in the above 2 cases was significantly different $(P<0.01)$, while the other 6 gave the same result between the dosing and the calculated dose based on creatinine clearance. Doctors at the hospital have attempted to make dose adjustments for these patients with renal failure complications, but there are still 2 cases (25\% error) in administering the dose, and of course, it is caused by the complexity of calculating the dose based on the patient's creatinine clearance so that it requires a computer application which makes it easier for the physician to take medical action [9]. 


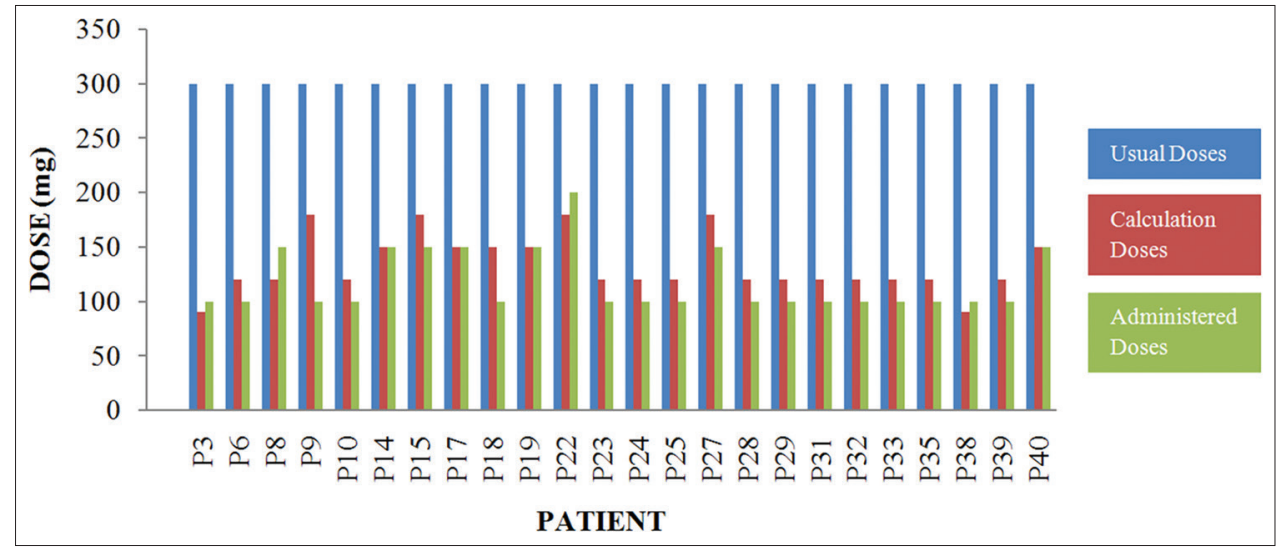

Fig. 3: Usual doses of ranitidine, doses administered at the hospital and dose calculations based on creatinine clearance

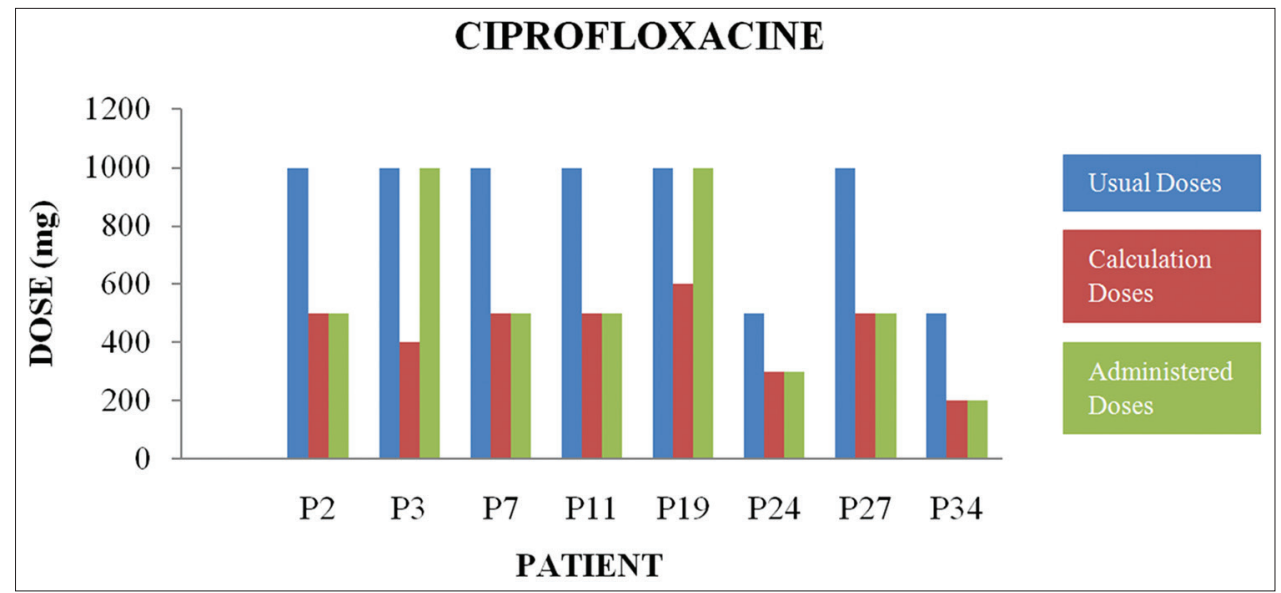

Fig. 4: Usual doses of ciprofloxacine, doses administered at the hospital and dose calculations based on creatinine clearance

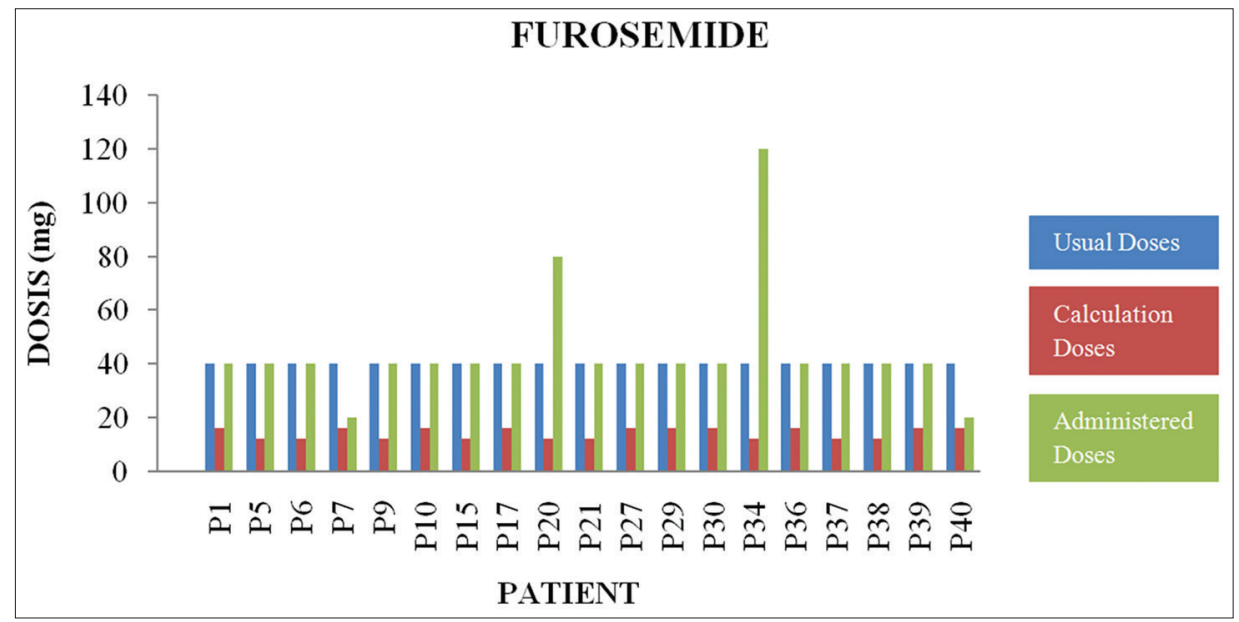

Fig. 5: Usual doses of furosemide, doses administered at the hospital and dose calculations based on creatinine clearance

Furosemide is indicated as diuretics for Edema and hypertension at doses of 20-40 mg/day for Udem, 80-120 mg/day for resistant Udem, and $40-80 \mathrm{mg} /$ day for hypertension therapy. For patients with renal failure, a larger dose of furosemide is $40-200 \mathrm{mg} /$ day [12]. This is because in patients with renal failure, there will be a decrease in bioavailability of furosemide [13]. Approximately $74 \%$ of furosemide is secreted in intact form through the kidneys [2]. Adjustment of furosemide dose for diabetic patients with renal failure was not calculated by the pharmacokinetics equation, and the patient's dose adjusted simultaneously with the patient's clinical response [10]. 19 of
19 cases of furosemide use are given in excess if calculated using clinical pharmacokinetics equations, and it is still considered safe because patients with kidney disorders have fluid accumulation but needs easier monitoring of drug delivery using VB.NET program integrated with pharmacokinetic formula.

15 of the 40 patients used ceftriaxone with a dose of $2 \mathrm{~g} /$ day, 2 patients with a dose of $1 \mathrm{~g} /$ day, and 1 patient with $4 \mathrm{~g} /$ day with intravenous administration (bolus). Pharmacokinetics ceftriaxone does not change in low-stage renal failure to moderate stage, but 


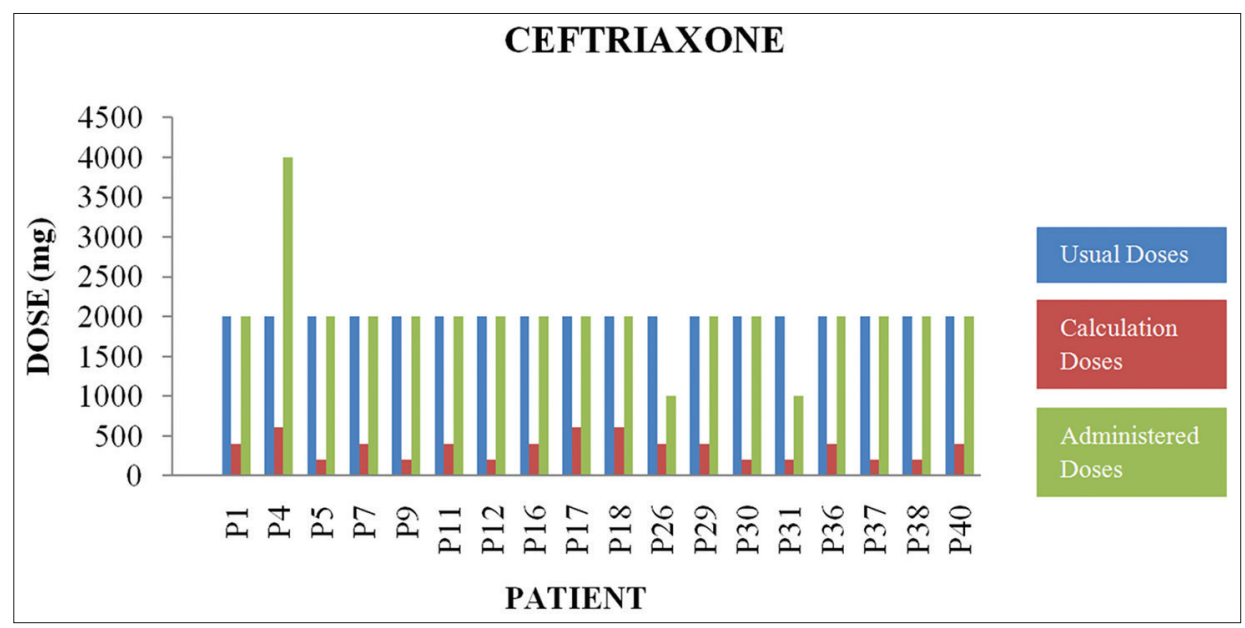

Fig. 6: Usual doses of ceftriaxone, doses administered at the hospital and dose calculations based on creatinine clearance

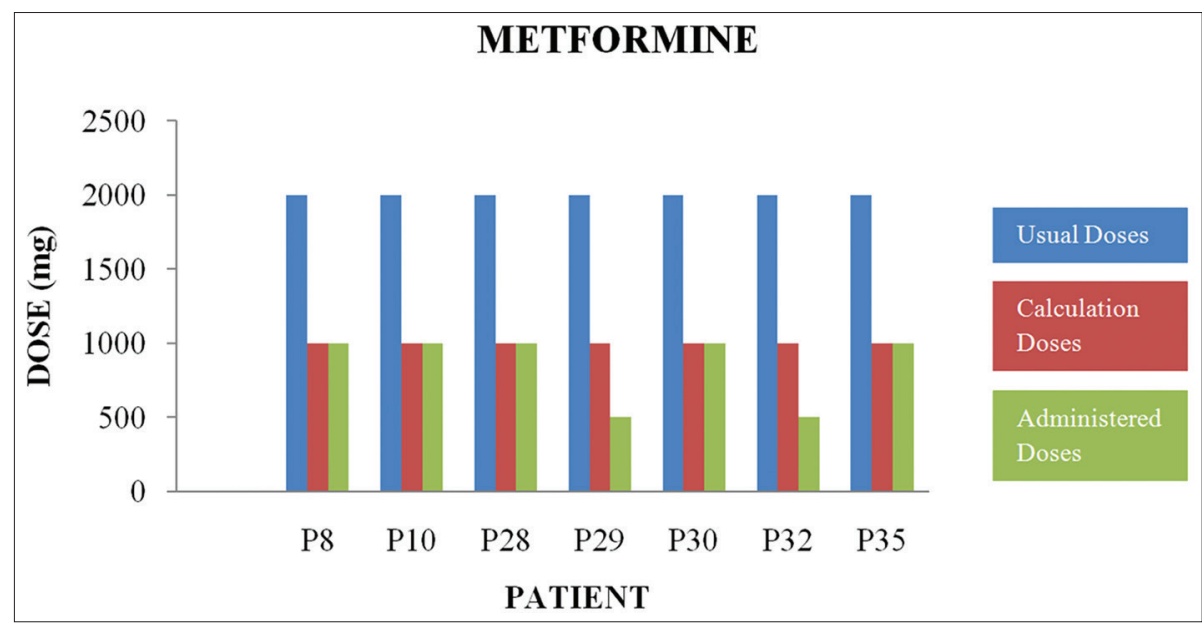

Fig. 7: Usual doses of metformine, doses administered at the hospital and dose calculations based on creatinine clearance

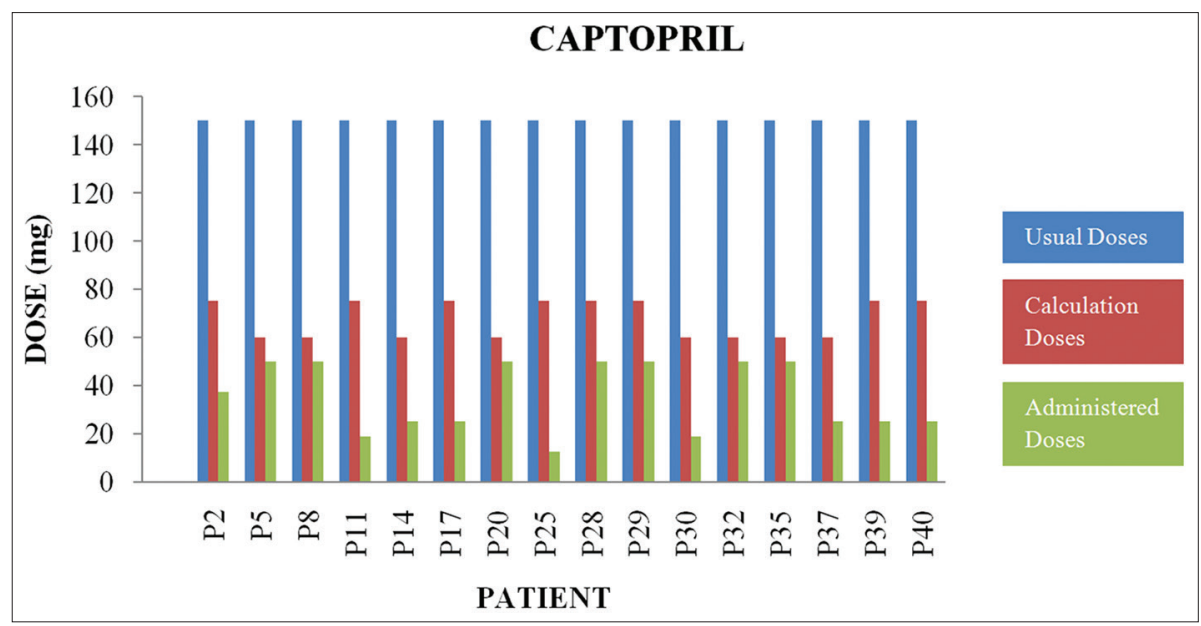

Fig. 8: Usual doses of captopril, doses administered at the hospital and dose calculations based on creatinine clearance

its half-life may be prolonged in severe stage renal failure to endstage renal failure. Dose adjustment is required for patients with severe renal failure, especially those with creatinine clearance of $<10 \mathrm{~mL} / \mathrm{min}$ with doses not exceeding $2 \mathrm{~g} /$ day [14]. 18 cases of 18 ceftriaxone administration exceeded the dose of pharmacokinetic calculation based on the patient's creatinine clearance using a computer dosing program [9].
Metformin is excreted in an unchanged form through the kidney of about $60 \%$ [10]. Metformin administration in patients with renal failure should be noted primarily in patients with creatinine clearance below $45 \mathrm{~mL} / \mathrm{min}$, whereas for patients with creatinine clearance $<30 \mathrm{~mL} / \mathrm{min}$ metformin use is avoided to avoid the effects of lactic acidosis. Lactic acidosis is a condition in which blood and acidity of the tissues increase as lactic acid accumulation increases. 
Table 1: Patients' demography

\begin{tabular}{ll}
\hline Characteristics & $\boldsymbol{n}(\%)$ \\
\hline Gender & \\
$\quad$ Male & $16(40)$ \\
Female & $24(60)$ \\
Age (years) & \\
$41-50$ & $10(25)$ \\
$51-60$ & $20(50)$ \\
$61-70$ & $10(25)$ \\
Creatinine clearance (mL/min) & \\
$50-80$ & - \\
$30-50$ & $2(5)$ \\
$=30$ & $15(37.5)$ \\
$<15$ & $23(57.5)$ \\
\hline
\end{tabular}

Table 2: Cases of Medication

\begin{tabular}{lllll}
\hline Medication & $\boldsymbol{n}$ & Excessive dosage & Less dosage & $\mathbf{\%}$ \\
\hline Ranitidine & 24 & 4 & 15 & 16.7 \\
Ciprofloxacin & 8 & 2 & - & 25 \\
Metformin & 7 & - & 2 & 0 \\
Captopril & 16 & - & 16 & 0 \\
Furosemide & 19 & 19 & - & 100 \\
Ceftriaxone & 18 & 18 & - & 100 \\
\hline
\end{tabular}

Captopril is excreted mostly by urine, 40-65\% in unchanged form. In patients with renal failure, peak plasma concentration of captopril will increase 2.5 times compared to patients with normal renal function [15]. The dose of captopril should be adjusted according to renal function of diabetic patients with renal failure, especially patients with creatinine clearance $<30 \mathrm{~mL} / \mathrm{min}$. The results showed that 16 cases of captopril use were less than the dose of pharmacokinetic calculations. In this case, doctors in hospitals have made efforts to decrease the dosage of captopril to avoid toxic effects but because the dose reduction is not mathematically calculated so that the dose of administration is considerably less than the dose that should be given.

\section{CONCLUSION}

Visual basic.net. succeed to calculate the individual dose for diabetic patients with renal failure quickly and easily, so VB.NET dose calculation program is needed by doctors in performing the right dose in patients with diabetes complications of kidney failure.

\section{ACKNOWLEDGMENT}

We gratefully thank to DP2M DIKTI (Directorate of Higher Education) Ministry of Research Technology and High Education, Indonesia through "Hibah Dosen Pemula" Research Grant 2017 for financial support in this study.

\section{CONFLICTS OF INTEREST}

All authors have none to declare.

\section{AUTHOR'S CONTRIBUTIONS}

Study conception

Acquisition of data

: Usman

Analysis of data

: Usman

Drafting of manuscript

: Zebua

Critical revision

:Zebua

REFERENCES

1. Dipiro JT, Talbert RL, Yee GC, Matzke GR, Wells BG, Polsey M. Pharmacotherapy a Pathophysiologic Approach. $7^{\text {th }}$ ed. New York: McGraw-Hill; 2008. p. 475-507.

2. Shargel L, Wu-Pong S, Yu AB. Applied Biopharmaceutics and Pharmacokinetics. $5^{\text {th }}$ ed. United States: The McGraw-Hill Companies; 2005.

3. Bauer LA. Clinical Pharmacokinetics Handbook. Washington, DC: McGram Hill; 2006.

4. Hewlet T. Nephrotoxic drug. Can Fam Phycisian 2004;50:709-11.

5. Falconnier AD, Haefeli WE, Schoenenberger RA, Surber C, Martin-Facklam M. Drug dosing in patient with renal failure optimized by immediate concurrent feedback. J Glob Inform Manag 2001;16:369-75.

6. Munar MY, Singh H. Drug dosing adjustment in patients with chronic kidney disease. Am Acad Fam Physician 2007;75:1487-96.

7. Faull FR. Prescribing in renal disease. Aust Prescr 2007;30:17-20

8. Patel M, Patel N, Nirmit S. Introduction to new features of visual basic 2010. Int J Adv Eng Technol 2010;1:10-5.

9. Usman A, Zebua NF. Design of individual dosing individual drawing applications using visual basic net programming based on pharmacokinetics data calculation. Sync J Inform Eng Res 2017;2:44-8.

10. Sweetman SC. Martindale. The Complete Drug Reference. $36^{\text {th }}$ ed. United States: The Phamaceutical Press; 2009.

11. Olivera ME, Manzo RH, Junginger HE, Midha KK, Shah VP, Stavchansky S. Biowaiver monographs for immediate release solid oral dosage forms: Ciprofloxacin hydrochloride. J Pharm Sci 2010;10:1-12.

12. Brater DC. Diuretic therapy. N Engl JMed 1998;339:387-95.

13. Siu-Kim C, Chan LK. Drug Dose in Patient with Rena Impairment. In: Lai KN, editor. A Practical Manual of Renal Medicine. Hongkong: World Scientific; 2009.

14. Patel IH, Sugihara JG, Weinfeld RE, Wong EG, Siemsen AW, Berman SJ. Ceftriaxone pharmacokinetics in patients with various degrees of renal impairment. Antimicrob Agents Chemother 1984;25:438-42.

15. Drummer OH, Workman BS, Miach PJ, Jarrot B, Louis WJ. The pharmacokinetics of captopril and captopril disulfide conjugates in uraemic patientson maintenance dialysis: Comparison with patients with normal renal function. Eur J Clin Pharmacol 1987;32:267-71. 